\title{
PELATIHAN FOTOGRAFI PRODUK KEPADA IKATAN REMAJA MASJID BAITURRAHMAN
}

\author{
Bobby Halim ${ }^{1)}$, Amaliatulwalidain2), Nike Anggraini ${ }^{3)}$ \\ 1)Program Studi Desain Komunikasi Visual, Fakultas Ilmu Pemerintahan dan Budaya, Universitas Indo Global Mandiri, \\ Kota Palembang, Sumatera Selatan, Indonesia \\ 2)Program Studi IImu Pemerintahan, Fakultas IImu Pemerintahan dan Budaya, Universitas Indo Global Mandiri, Kota \\ Palembang, Sumatera Selatan, Indonesia \\ 3)Program Studi Bahasa Inggris, Fakultas Keguruan dan Ilmu Pendidikan, Universitas Indo Global Mandiri, Kota \\ Palembang, Sumatera Selatan, Indonesia \\ Corresponding author: Bobby Halim \\ E-mail : bobby_dkv@uigm.ac.id
}

Diterima 11 Oktober 2021, Direvisi 01 November 2021, Disetujui 01 November 2021

\begin{abstract}
ABSTRAK
Kegiatan pelatihan Fotografi Produk di IRMA Baiturrahman merupakan respon dari pihak terkait. Di tengah kondisi pandemi ini, industri kreatif terus digalakan oleh pemerintah Indonesia. Bidang Fotografi memiliki kesempatan tersendiri saat ini, dikarenakan pandemi yang menyerang Indonesia berakibat perubahan gaya hidup masyarakatnya. Akibat pandemi,masyarakat Indonesia lebih banyak menghabiskan waktu dengan daring/online karena melalui daring masyarakat masih dapat beraktivitas sehari-hari,dari bekerja, belajar hingga menikmati hiburan. Universitas Indo Global Mandiri Palembang, berkomitmen untuk selalu berusaha melakukan pengabdian terhadap masyarakat secara terus menerus sebagai wujud kepedulian insan akademik terhadap peningkatan kualitas hidup masyarakat. Untuk itu Tim Pengabdian Masyarakat Universitas Indo Global Mandiri Palembang bermaksud menjalin kemitraan dengan IRMA Baiturrahman dengan skema pengabdian internal, yaitu 1) Memberikan wawasan mengenai Fotografi dan pengetahuan mengenai perkembangan fotografi. 2) Memberikan keterampilan Fotografi Produk terhadap peserta pelatihan. 3) Memberikan pengetahuan dan wawasan dalam pembuatan Fotografi Produk. 4) Meningkatkan keterampilan bagi peserta yang sudah memiliki dasar dalam Fotografi. 5) Memberikan motivasi dan kiat-kiat kepada peserta agar dapat menjadi pribadi yang mandiri dan mampu menghasilkan Fotografi Produk secara berkala. Metode yang dipakai pada Kegiatan pelatihan Fotografi Produk ini yaitu Metode Sosialisasi dan Ceramah, Metode Demonstrasi \& Metode Bimbingan \& Partisipatif. Kegiatan pelatihan Fotografi Produk di IRMA Baiturrahman menghasilkan beberapa foto produk dengan fungsi yang bervariasi.
\end{abstract}

Kata kunci: fotografi produk; remaja ; IRMA baiturrahman.

\begin{abstract}
The Product Photography training activity at IRMA Baiturrahman is a response from related parties. In the midst of this pandemic, the Indonesian government continues to promote the creative industry. The field of photography has its own opportunity at this time, because the pandemic that attacked Indonesia resulted in changes in the lifestyle of its people. As a result of the pandemic, Indonesian people spend more time online because online people can still do their daily activities, from work, study to enjoying entertainment. Indo Global Mandiri University Palembang, is committed to always trying to do community service continuously as a form of concern for academics to improve the quality of life of the community. For this reason, the Community Service Team of Indo Global Mandiri University Palembang intends to establish a partnership with IRMA Baiturrahman with an internal service scheme, namely 1) Providing insight into Photography and knowledge about the development of photography. 2) Provide Product Photography skills to trainees. 3) Provide knowledge and insight in the manufacture of Product Photography. 4) Improve skills for participants who already have a foundation in Photography. 5) Provide motivation and tips to participants so that they can become independent individuals and are able to produce Product Photography on a regular basis. The methods used in this Product Photography training activity are the Socialization and Lecture Method, the Demonstration Method \& the Guidance \& Participatory Method. Product Photography training activities at IRMA Baiturrahman produced several product photos with various functions.
\end{abstract}

Keywords: product photography; teenager; IRMA baiturrahman. 


\section{PENDAHULUAN}

\section{Analisis Situasi}

Pemuda-pemudi merupakan aset berharga bagi sebuah negara. Mengapa disebut aset berharga, karena mereka yang akan menjadi sumber daya manusia yang diperlukan sebagai roda penggerak perekonomian masyarakat Indonesia. Indonesia memiliki sekitar 270 juta jiwa per tahun 2019, dan sekitar $24 \%$ nya adalah tingkat pemuda dengan angka sekitar 64 juta jiwa. Hal ini dapat menjadi pisau bermata dua, maksudnya yaitu dengan total jumlah penduduk usia muda tersebut dapat menjadi keuntungan maupun kerugian bagi bangsa Indonesia.

Keuntungan dengan jumlah usia muda yang besar tersebut yaitu melimpahnya persediaan tenaga kerja dengan berbagai latar belakang pendidikan maupun skill. Tentu hal ini menjadikan persaingan kompetitif dan sehat. $\mathrm{Di}$ samping keuntungan, kekurangan dari besarnya usia muda tersebut yaitu rentan dengan jumlah pengangguran yang tinggi. Mengapa dapat seperti itu? Karena tidak sebandingnya jumlah tenaga kerja dengan lapangan kerja yang tersedia, lalu masih repotnya birokrasi dalam mengurus ijin usaha.

Era saat ini tidak hanya saja persaingan yang keras akan tetapi pandemi mengubah pola aktivitas manusia sehingga ada perlambatan dalam dinamika kehidupan. Apalagi pemerintah saat ini berkali-kali menerapkan pembatasan kegiatan maupun aktivitas di luar rumah, sehingga roda perekonomian menjadi terganggu. Bagai bola salju dan efek domino, dari masalah kecil dapat menjadi masalah besar, masalah bersama.

Tujuan dari pelatihan ini yaitu agar peserta pelatihan memiliki kemampuan fotografi tingkat dasar dan menengah. Kemampuan fotografi tingkat dasar hampir semua peserta memilikinya, tapi kemampuan tingkat menengah hanya beberapa saja yang sudah paham.

Sumatera Selatan secara nasional di peringkat 10 besar dalam PENDAPATAN PEMERINTAH PROVINSI, sedangkan secara pulau (Sumatera) termasuk 3 besar. Artinya, provinsi Sumatera Selatan memiliki nilai ekonomi yang sangat tinggi. Palembang sebagai ibukota dari provinsi Sumatera Selatan menjadi daerah prioritas roda pergerakan perekonomian. Banyak elemen yang terdapat di Palembang, dari sektor pemerintahan, pendidikan hingga sektor usaha dan jasa.

Amat disayangkan apabila Sumber Daya Manusia SDM di Palembang dan sekitarnya kalah bersaing secara Nasional, padahal seperti di paragraf sebelumnya, ekonomi berpusat di kota Palembang. Menjadi pertanyaan besar, kenapa SDM di Palembang kurang mampu bersaing, dalam hal industri kreatif, dibandingkan dengan provinsi- provinsi lain di Indonesia.

Ikatan Pemuda Masjid Kebun Bunga terdiri dari pemuda-pemudi yang berusia belasan hingga 20 tahun awal. Mayoritas merupakan lulusan SMA dan sebagian sedang menempuh pendidikan kuliah. Latar belakang pendidikan mereka pun beragam, ada yang IPA,IPS maupun SMK, dan yang sedang kuliah menempuh jurusan yang beragam pula. Pada saat pandemi saat ini, banyak perusahaan baik skala mikro,kecil hingga besar yang terdampak sehingga tidak sedikit perusahaan yang merampingkan SDM-nya dengan cara dirumahkan maupun melalui Pemutusan Hubungan Kerja. Tidak ada yang tahu keadaan ini berlangsung sampai kapan. Maka dari itu, kami dari pihak Universitas Indo Global Mandiri khususnya program studi Desain Komunikasi Visual akan memberi bekal pelatihan kepada Ikatan Pemuda Masjid Kebun Bunga berupa pelatihan Fotografi Produk.

Fotografi sebenarnya bukan hal yang asing lagi bagi setiap penduduk kota. Tetapi banyak cabang ilmu dari Fotografi, seperti Foto Model, Foto Produk, Foto Jurnalistik hingga Foto Dokumentasi Pernikahan. Materi pembelajaran Fotografi saat ini sudah banyak tersedia, baik versi cetak maupun digital, versi buku maupun video. Meski tersebarnya materi pembelajaran Fotografi dimana-mana, ada beberapa hal mengapa Fotografi di Palembang masih belum optimal. Beberapa faktor-nya yaitu:

1. Toko buku yang tidak banyak.

2. Buku Fotografi, khususnya mengenai Fotografi Produk masih sulit didapatkan.

3. Akses dan kecepatan internet yang belum merata di Palembang, sehingga ini cukup menyulitkan masyarakat Palembang untuk mencari dan mendapatkan materi Fotografi Produk.

4. Pandemi menyebabkan masyarakat Palembang memprioritaskan kebutuhan primer daripada kebutuhan sekunder dan tersier. Maksudnya, lebih penting memenuhi kebutuhan perut (primer) daripada kebutuhan pendidikan (sekunder) sebagai penunjang usaha dan pekerjaan.

\section{METODE}

Metode dalam sebuah pelatihan keahlian merupakan bagian yang krusial untuk mencapai keberhasilan sebuah pelatihan, apalagi berkaitan dengan pelatihan Keterampilan dasar Fotografi Produk, karena tidak semua peserta memiliki fondasi atau keterampilan dalam Keterampilan Fotografi Produk. Sebagian dari peserta tentunya benar- 
benar sebagai pemula dalam mengolah foto menjadi Fotografi Produk. Secara garis besar target pelatihan Keterampilan dasar Fotografi Produk bagi Ikatan Pemuda Masjid Kebun Bunga adalah memberikan keterampilan secara teknis.

Adapun dasar yang diterapkan adalah prinsip dasar fotografi, sedangkan teknik yang berkaitan dengan digital adalah mengolah foto mentah menjadi lebih matang ,lalu digabungkan dengan teks maupun elemen grafis lainnya sehingga menjadi Foto Produk.

Pelatihan Fotografi Produk di IRMA Baiturrahman yang berada di Kecamatan Sukarami Kelurahan Kebun Bunga Kota Palembang pada 29 Agustus 2021 diikuti oleh 19 peserta dari tingkat SD hingga tingkat SMA. Adapun tahapan pelaksanaan yang digunakan dalam pelatihan Keterampilan dasar Fotografi Produk bagi Ikatan Pemuda Masjid Kebun Bunga adalah sebagai berikut:

1. Penulis melakukan wawancara singkat dengan ketua IREMA Masjid Baiturrahman, hal apa yang belum dikuasai oleh anggota IREMA Masjid Baiturrahmandalam bidang Seni Rupa dan Desain.

2. Setelah mengetahui jenis pelatihan yang akan dibawakan, penulis menyiapkan materi, alat dan bahan untuk pelatihan.

3. Pada hari yang sudah disepakati oleh penulis dan mitra, disini yaitu IREMA Masjid Baiturrahman, maka dilaksanakan pelatihan sesuai rencana hingga selesai.

Tahap Pelaksanaan Kegiatan

1. Metode Sosialisasi dan Ceramah, metode ini dapat diartikan sebagai presentasi materi yang berkenaan dengan teori Keterampilan dasar Fotografi Produk, langkah-langkah proses pembuatan Keterampilan dasar Fotografi Produk,hingga strategi pengembangan desain Keterampilan dasar Fotografi Produk

2. Metode Demonstrasi, yaitu dengan cara praktik secara langsung di depan peserta pelatihan mengenai hal-hal yang bersifat teknis. Adapun langkah-langkah yang digunakan dalam pelatihan Keterampilan dasar Fotografi Produk ini di antaranya adalah pemahaman teori prinsip dasar Fotografi, prinsip Foto Produk dan Pengolahan Foto Mentah menjadi Foto Produk yang Matang. Beberapa langkah tersebut terlebih dahulu diberikan pengenalan terhadap peserta pelatihan.

3. Metode Bimbingan dan Partisipatif.

Metode ini diterapkan ketika proses pelatihan dilaksanakan. Secara teknis metode ini dilakukan melalui pemantauan secara langsung terhadap masing-masing peserta, dan kemudian memperagakan teknik-teknik Keterampilan dasar Fotografi Produk.

Tahap Evaluasi

4. Metode Evaluasi.

Secara garis besar metode evaluasi dapat dipahami sebagai proses untuk mengukur atau menilai apakah suatu kegiatan atau program yang dilaksanakan sesuai dengan tujuan yang ingin dicapai. Dalam pelatihan Keterampilan dasar Fotografi Produk bagi Ikatan Pemuda Masjid Kebun Bunga evaluasi yang dilakukan berkaitan dengan penguasaan teknik dasar dalam Keterampilan dasar Fotografi Produk, proses produksi, penerapan dari foto entah menjadi foto matang, kualitas foto yang dihasilkan.

\section{HASIL DAN PEMBAHASAN}

Kegiatan pelatihan Fotografi Produk di IRMA Baiturrahman yang diikuti oleh 19 peserta dibuka dengan sambutan dari ketua IREMA Masjid Baiturrahman pada gambar 2.

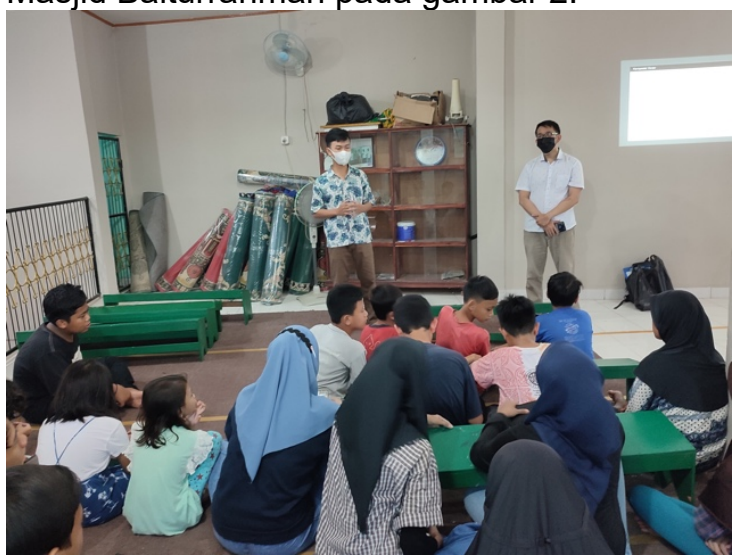

Gambar 1. Sambutan Ketua IRMA

Baiturrahman

(Sumber : Siddik)

Selanjutnya kegiatan pelatihan sepenuhnya diserahkan kepada tim PKM dengan melakukan ceramah seperti pada gambar 2.

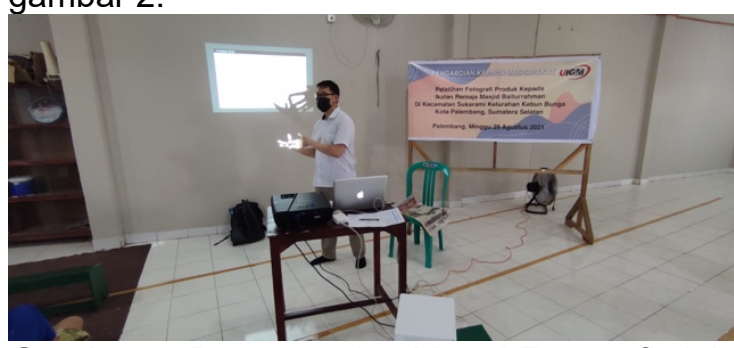

Gambar 2. Penyampaian Materi Fotografi oleh Penulis menggunakan Powerpoint

(Sumber : Siddik)

Para peserta mengikuti pelatihan dengan seksama dan langsung mempraktikan 
untuk keperluan bahan ajarnya seperti pada Gambar 3

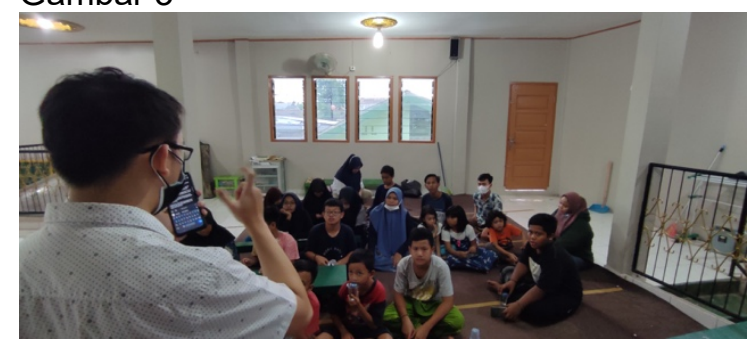

Gambar 3. Para peserta memperhatikan pelatihan dengan seksama

(Sumber : Siddik)

Para peserta langsung mempraktikan teori yang sudah didapat dari presentasi yang disampaikan oleh penulis, seperti pada gambar 4

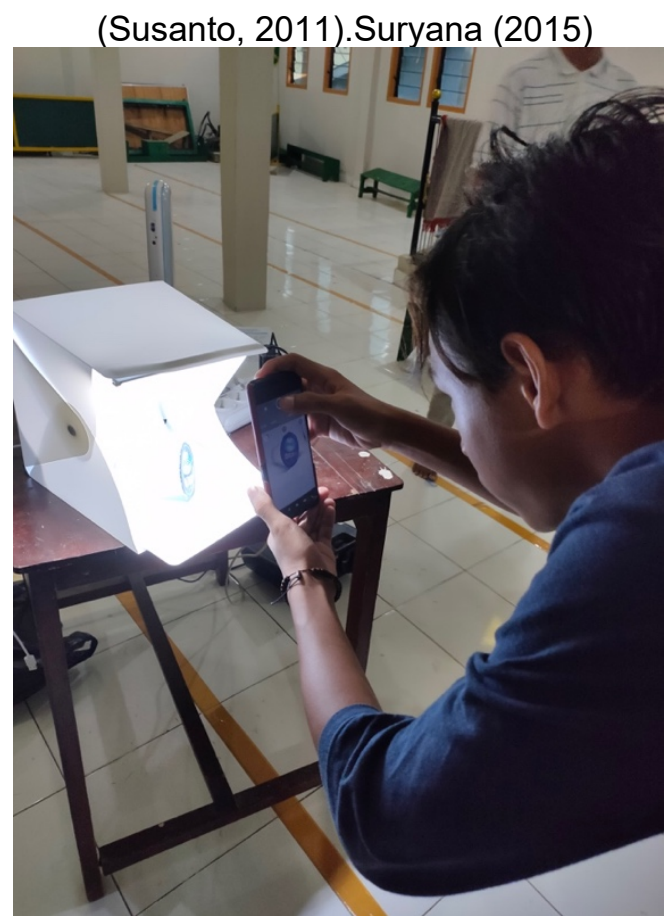

Gambar 4. Anggota IRMA Baiturrahman mempraktekan Fotografi Produk (Sumber : Bobby Halim)

Berikut adalah hasil dan luaran yang dicapai selama kegiatan pelatihan Fotografi Produk di IRMA Baiturrahman seperti yang terlihat pada Gambar 5 dan Gambar 6.

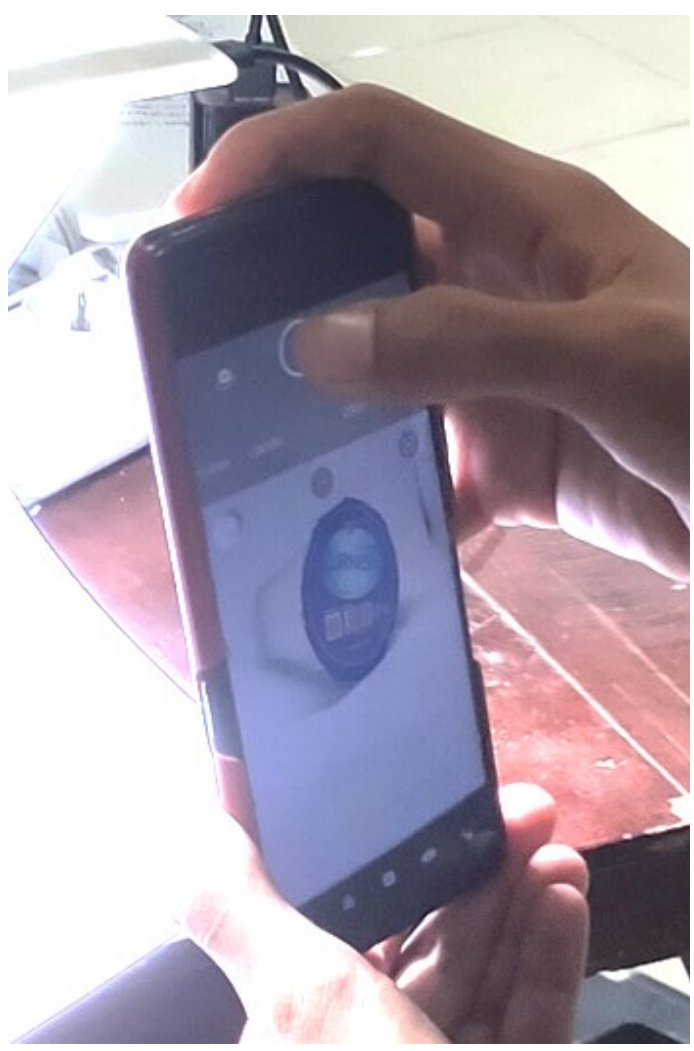

Gambar 5. Hasil Foto Anggota IRMA Baiturrahman (Sumber : Bobby Halim)

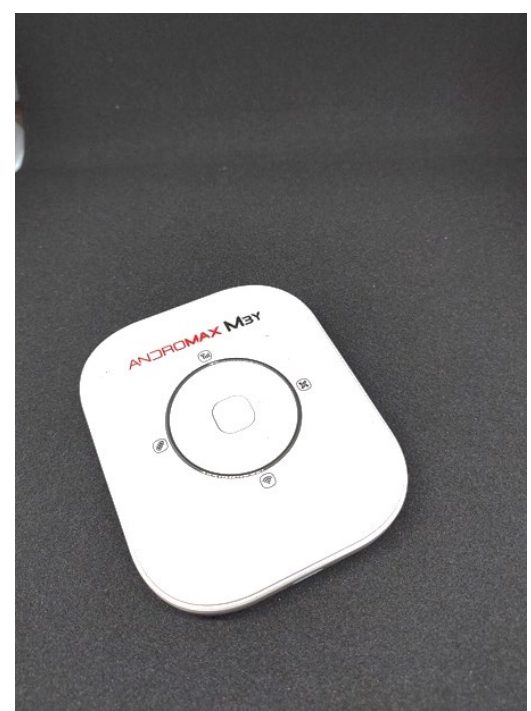

Gambar 6. Hasil Foto Anggota IRMA Baiturrahman (Sumber : Bobby Halim)

Acara pelatihan ditutup dengan foto bersama tim PKM UIGM dan para peserta seperti pada Gambar 7. 


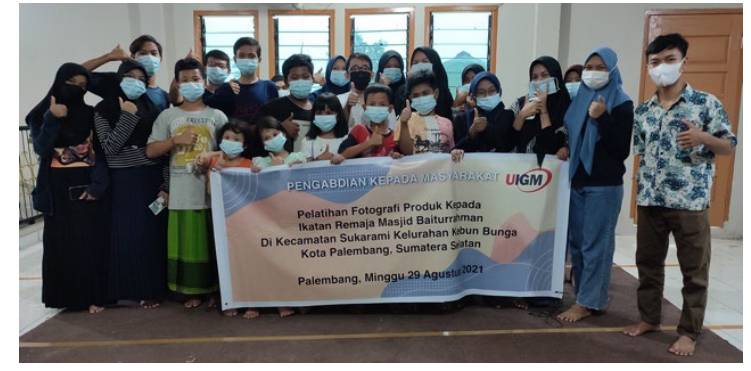

Gambar 7. Foto Pelatih bersama IRMA Baiturrahman

(Sumber : Siddik)
Pustaka Utama.

Simon, S., \& Rickman, R. (2014). Komposisi: Dari Foto Biasa Jadi Luar Biasa. Jakarta: Elex Media Komputindo.

Suryana, J. (2015). Tinjauan Seni Rupa. Yogyakarta: Graha Ilmu.

Susanto, M. (2011). Diksi Rupa: Kumpulan Istilah Seni Rupa. Yogyakarta: ISI Yogyakarta.

Zahar, I. (2017). 11 Kiat Jitu Fotografer Profesional. Jakarta: Elex Media Komputindo.

\section{SIMPULAN DAN SARAN}

Semua peserta yang ikut pelatihan ini dapat membuat karya Foto Produk dengan tingkat kemampuan yang berbeda. Untuk itu bagi peserta yang kemampuan tekniknya masih rendah dapat mendalaminya pada kesempatan selanjutnya. Selain itu, Peserta pelatihan ini memiliki peluang untuk bersaing di tingkat Kota maupun Provinsi, karena didukung dengan peralatan yang mumpuni. Selanjutnya yaitu kekurangan yang dapat dicermati dari peserta adalah aspek kreativitas, karena hampir sebagian besar peserta belum memiliki wawasan yang luas akan Foto Produk. Dan yang terakhir, secara keseluruhan hasil pelatihan ini perlu adanya tindak lanjut agar IRMA Baiturrahman dapat menjadi inkubator wirausaha- wirausaha muda di kemudian hari.

\section{UCAPAN TERIMAKASIH}

Pertama penulis mengucap syukur kepada Tuhan Yang Maha Esa yang telah memberikan kelimpahan berkat kesehatan jasmani dan rohani. Terimakasih kepada Ketua Program Studi Desain Komunikasi Visual Universitas Indo Global Mandiri Bapak Yosef Yulius yang sudah mendukung kegiatan ini. Terimakasih kepada Universitas Indo Global Mandiri yang sudah mendukung kegiatan PKM ini baik secara materiil maupun non-materiil. Juga terimakasih kepada Ikatan Remaja Masjid (IRMA) Baiturrahman yang terletak di Kelurahan Kebun Bunga Kota Palembang yang sudah menerima Tim Pengabdian Kepada Masyarakat (PKM) Universitas Indo Global Mandiri dalam berbagi ilmu.

\section{DAFTAR RUJUKAN}

Bayu, D. J. (2020). Rasio Pemuda Indonesia Cenderung Menurun dalam Satu Dekade Terakhir. Retrieved from Databoks Katadata website: https://databoks. katadata.co.id/datapublish/2020/12/23/ra sio-pemuda-indonesia-cenderungmenurun-dalam-satu-dekade-terakhir

Koentjarajingrat. (1997). Metode-Metode Penelitian Masyarakat. Jakarta: Gramedia 